\title{
Overcoming the disconnect: are paleolimnologists doing enough to make their science accessible to aquatic managers and conservationists?
}

\author{
Émilie Saulnier-Talbot* \\ Laboratoire de Paléoécologie Aquatique, Université Laval, Québec, QC, Canada
}

Keywords: Paleolimnological approach, adaptive management, restoration, conservation, sustainability, data bases

Progress in adaptive management and conservation of ecosystems cannot take place without direct collaboration between academics and practitioners. Hence, one of the most important challenges facing the development of sustainable solutions to current and future environmental problems is finding ways to bridge the gap between fundamental research and applied management, conservation and restoration of ecosystems. Here, I call on the paleolimnological community to help adaptive management move forward by making a more effective contribution of academic advancements on long-term aquatic ecology to the resolution of environmental problems. I present a personal view of how forging more links with environmental managers, conservationists, and the public, and by more effectively adapting and sharing our data and tools, can advance sustainable solutions to the many problems facing aquatic ecosystems all over the world.

Because of their essential nature, freshwaters have always been significantly impacted by human activities. Today, countless lakes, wetlands and rivers require that efforts be made to restore their health and through this, hopefully, the ecosystem services they provide. The task is overwhelming and many lake-types are notoriously difficult to manage and restore (e.g., shallow lakes: Jeppesen et al., 2007; tropical lakes: Lewis, 2000). For this reason, a vast number of people from various fields and with assorted competences must be involved and work together toward common goals. To achieve this, they must find common process and purpose in their interactions.

Over the past decades, the case has been amply made in the scientific literature for the usefulness of paleolimnology in assessing aquatic ecosystem health and aiding the management of lakes (e.g., see Bennion et al., 2011 and references therein). Doubtless the paleolimnological research community is largely convinced of the paramount value of the long-term perspective that the investigation of lake sediment archives can provide to inform sound management practices and develop realistic restoration targets. It is true that paleolimnology has already made great strides over the past 30 years to become more widely accepted, especially within other related scientific disciplines. However, discussions with colleagues and a recent brief incursion into the world of environmental conservation NGOs made me realize that paleolimnology is unfortunately not yet the household word that we would wish it to be within conservation circles. Paleolimnology still remains too infrequently used in aquatic and wildlife management practices. This led me to reflect on how we as paleolimnologists, could find ways to make our tools and data more user-friendly to managers and conservationists of aquatic environments. Moreover, through this process, I asked myself how we can better promote the idea that the integration of the paleolimnological approach is paramount in the development of sound environmental management strategies and policies. If we wish paleolimnology to enable science-based decision making for improving 
the health of in-land aquatic ecosystems, I believe that we should endeavor to find effective ways to present and promote it with conservation practitioners, managers and policy makers.

In a recent paper, Gillson and Marchant (2014) singled-out the two main issues hindering the application of long-term paleoecological data in management and conservation of ecosystems: (1) management and policy implications are not clearly formulated, and (2) data sets are not accessible or amenable to stakeholders. To this, I should like to add that: the paleoecological approach is insufficiently known and not well understood. So, what can we, as a mostly academic community, do about this? Admittedly, academics (or anyone else doing fundamental research) are seldom consulted on management policy. But instead of waiting to be called upon to explain how our approach can be applied to benefit management, we should aim to be more pro-active and consciously seek-out the people who are directly implicated in management and policy. Discussions with stakeholders can be enlightening and lead us to discover the needs they have singled-out. Attending meetings of community watershed counsels are a good way of making direct contact with the population and with elected representatives. Getting to know the concerns and preoccupations of residents and local officials about their water bodies can contribute to steering research and to the establishment of community-endorsed goals for aquatic ecosystem health. It is also a good way to become better informed and, eventually, of taking part in counseling local management and policy. Identifying restoration and conservation needs in conjunction with managers, conservation practitioners and the public before embarking on a research project with the goal of including them from the start as inherent facets of the research is indeed a promising avenue for academics. Public involvement is paramount to successful conservation, therefore it is also important to follow-up with communities on the advancement and success of restoration and conservation projects and better still, to encourage them to participate in some way, whenever possible.

The problem of the accessibility of data sets to stakeholders is more complex. Even amongst ourselves, we are sometimes reluctant to share data and, consciously or not, we make it difficult for others to use it. Let's take for example, what I like to call "the transfer function problem." With the advent of transfer functions and their statistical refinement over the past 20 plus years, we have developed some powerful and reliable tools that make quantitative inferences of past environmental changes possible. However, many of the published models lack some basic information to make them applicable by researchers other than the ones who developed them. Namely, because they do not include the necessary information for taxonomical harmonization of the sedimentary data sets with the modern (model) set. This shortcoming is a major obstacle to the accessibility of a model to the research community at large and is hindering progress and productivity. As the paleolimnological community grows, more and more research is being carried-out in areas that were once the strongholds of only a few. The accessibility of inference models thus becomes an issue that should be addressed. Then, again, some are of the opinion that many in the paleolimnological community are starting to move away from inference models as we know them. In truth, there are a number of problems with quantitative reconstructions from biological proxies which should not be ignored (see Juggins, 2013), but are beyond the scope of this paper. However, it is worth mentioning that great strides have been made using this approach and its use at present can hardly be discarded as obsolete. As Box and Wilson (1951) famously wrote: "essentially, all models are wrong, but some are useful." Therefore, until we develop more useful hindcasting techniques, I believe inference models will remain an important component of our toolkit.

In my opinion, transfer functions should be made easily available to those who wish to apply them, by including the necessary datasets and taxonomical references in the publications. This can take the form of an appendix or supplementary material in a paper, a web page, or a fully-fledged taxonomic guide. For the sake of accessibility, I would even go so far as to suggest creating an official repository of paleolimnological data, where transfer functions and downcore data could be archived and made available to those who wish to use them. Perhaps the best place to house this archive would be through the website of the International Paleolimnological Association (IPA) (http://paleolim. org/). Also, an updateable list of publications dealing specifically with the use of the paleolimnological approach in management, restoration and conservation could be drawn-up and made available on the IPA website.

That the paleoecological approach still remains insufficiently known and not well understood necessitates still more effort on our part. Of course, many paleolimnologists have already invested immense energy into synthesizing information on tools and techniques [e.g. Developments in Paleoenvironmental Research Book Series, edited by Smol (2001)]. There are also more and more paleolimnologists working outside academia, in government and consulting positions, where they can influence decision-making and promote the approach. But, as a whole, it appears that we have not yet risen up to the challenge issued by Smol (1995) to "continue developing techniques and approaches that can provide these (paleolimnological) data in a form that is meaningful to other scientists and managers." One example of this is the downcore plot. It might appear trivial, but presenting data on a vertical scale instead of the more common horizontal scale can turn many people off, especially when it is accompanied by a host of very unfamiliar species names. There are some examples in the literature of downcore data presented in the more intuitive left-right plots (e.g., Renberg, 1990; Wolfe, 2003) and I think this could be a good way of engaging a non-paleo audience in publications and presentations that are aimed primarily at them. At a more meaningful scale, perhaps the time is ripe for paleolimnologists to attempt to develop indicators specifically aimed at improving and evaluating restoration success. This is being done for terrestrial ecosystems, where protocols and models have been created that help to predict the success or failure of restoration efforts on degraded ecosystems throughout the restoration process (e.g., González et al., 2014). It would also be useful to attempt to develop macroecological restoration strategies based on lake-types and/or at regional scales. Environmental managers and conservationists often use pre-defined ecozones (such as presented in Ménard et al., 2013), which help to guide their efforts at a regional scale. Structuring paleolimnological tools (such as transfer functions, for example) on the same ecozones could to 
some degree facilitate the application of certain tools by conservation practitioners. It is a question of becoming familiar with the way that managers and practitioners work and incorporating some aspects of their vision into the way we produce knowledge so that it can be useful to everyone. In other words, learning to speak the same language is a good way forward.

Another way to make our science better known and better accepted as an inherent component of aquatic management is assuredly by promoting dialog and engaging many audiences. To this end it is important for those of us interested in making a contribution to the improvement of lake management, to take part in forums and conferences in the applied conservation and management sector. A larger proportion of our community should strive to engage with the media and use social media to share the paleoecological understanding of ecosystem value, whether it be through interviews or blogs or opinion articles (such as this one). Most importantly, for those who have the privilege of mentoring students, include this type of activity in academic training of future paleolimnologists.

Inevitably, many of us will be confronted by resistance to the incorporation of the paleolimnological approach in management strategies (the ever present resistance to change). Paleolimnology and biomonitoring have the reputation of being costly and lengthy, with results that are not always straightforward. To change this mentality, we need to continue to consistently make the point that the results are worth the resources, time and effort invested. Presenting concrete examples of successful restoration projects that have employed the paleolimnological approach, such as the case studies included in Smol (2008), and the papers contained within this special issue, will no doubt be very useful.

\section{References}

Bennion, H., Battarbee, R. W., Sayer, C. D., Simpson, G. L., and Davidson, T. A. (2011). Defining reference conditions and restoration targets for lake ecosystems using palaeolimnology: a synthesis. J. Paleolim. 45, 533-544. doi: 10.1007/s10933-010-9419-3

Box, G. E. P., and Wilson, K. B. (1951). On the experimental attainment of optimum conditions (with discussion). J. R. Stat. Soc. B 13, 1-45.

Gillson, L., and Marchant, R. (2014). From myopia to clarity: sharpening the focus of ecosystem management through the lens of paleoecology. Trends Ecol. Evol. 29, 317-325. doi: 10.1016/j.tree.2014.03.010

González, E., Rochefort, L., Boudreau, S., and Poulin, M. (2014). Combining indicator species and key environmental and management factors to predict restoration success of degraded ecosystems. Ecol. Ind. 46, 156-166. doi: 10.1016/j.ecolind.2014.06.016

Jeppesen, E., Meerhoff, M., Jacobsen, B. A., Hansen, R. S., Søndergaard, M., Jensen, J. P., et al. (2007). Restoration of shallow lakes by nutrient control and biomanipulation - the successful strategy varies with lake size and climate. Hydrobiologia 581, 269-285. doi: 10.1007/s10750-006-0507-3

Juggins, S. (2013). Quantitative reconstructions in paleolimnology: new paradigm or sick science? Q. Sci. Rev. 64, 20-32. doi: 10.1016/j.quascirev.2012.12.014

Lewis, W. M. Jr. (2000). Basis for the protection and management of tropical lakes. Lakes Reserv. Res. Manag. 5, 35-48. doi: 10.1046/j.1440-1770.2000.00091.x

Ménard, S., Darveau, M., and Imbeau, L. (2013). The importance of geology, climate and anthropogenic disturbances in shaping boreal wetland and aquatic landscape types. Ecoscience 20, 399-410. doi: 10.2980/20-4-3628
Paleolimnologists unquestionably have an important role to play in the development of sustainable adaptation and aquatic ecosystem management strategies. It is high time that we, as a research community, and not just a few among us, start engaging more in the processes that will lead to the effective implementation of these strategies leading to better management, preservation and restoration of aquatic ecosystems. The analysis and interpretation of paleolimnological data remains (and will remain) largely confined to specialists in academia. However, we can engage in a variety of ways to bridge the gap between the needs of management to address "real-world" problems and the orientation of publicly funded fundamental research. I am hopeful that this opinion piece will be thoughtprovoking and will contribute to move things forward. It is up to us, paleolimnologists, to meet the challenge of making our science, including our knowledge, our data, our techniques and our tools, more widely known, available and palatable to managers, conservationists and the general interested public.

\section{Acknowledgments}

I would like to thank Isabelle Larocque-Tobler for encouraging me to write this opinion piece and Isabelle Lavoie, Roxane Tremblay and Stéphane Boudreau for fruitful discussions on the subject of bridging the gap between fundamental research and applied ecosystem management. Finally, I wish to thank John Smol for providing me with his incomparable insight into this subject and offering constructive comments to help improve this paper.

Renberg, I. (1990). A 12,600 year perspective of the acidification of Lillä Öresjön, southwest Sweden. Philos. Trans. R. Soc. B 327, 357-361. doi: $10.1098 /$ rstb.1990.0073

Smol, J. P. (ed). (2001). Developments in Paleoevironmental Research Book Dordrecht: Series, Springer.

Smol, J. P. (1995). "Paleolimnological approaches to the evaluation and monitoring of ecosystem health: providing a history for environmental damage and recovery," in Evaluating and Monitoring the Health of Large-Scale Ecosystems, NATO ASI Series Vol. 128, eds D. J. Rapport, C. L. Gaudet, and P. Calow (Berlin; Heidelberg: Springer-Verlag), 301-318.

Smol, J. P. (2008). Pollution of Lakes and Rivers: a Paleoenvironmental Perspective. 2nd Edn. Oxford: Wiley-Blackwell Publishing.

Wolfe, A. P. (2003). Diatom community responses to late-Holocene climatic variability, Baffin Island, Canada: a comparison of numerical approaches. Holocene 13, 29-37. doi: 10.1191/0959683603hl592rp

Conflict of Interest Statement: The author declares that the research was conducted in the absence of any commercial or financial relationships that could be construed as a potential conflict of interest.

Copyright (c) 2015 Saulnier-Talbot. This is an open-access article distributed under the terms of the Creative Commons Attribution License (CC BY). The use, distribution or reproduction in other forums is permitted, provided the original author(s) or licensor are credited and that the original publication in this journal is cited, in accordance with accepted academic practice. No use, distribution or reproduction is permitted which does not comply with these terms. 